\title{
EFFECT OF PROCESS PARAMETERS ON TEMPERATURE DISTRIBUTION, STRAIN RATE AND FLOW-STRESS DURING FRICTION STIR WELDING OF ALUMINIUM ALLOY
}

\author{
Mohd Anees Siddiqui ${ }^{1}$, S.A.H. Jafri ${ }^{2}$, K.M.Moeed ${ }^{3}$ \\ ${ }^{1}$ University Polytechnic, Integral University Lucknow, India \\ ${ }^{2}$ Department of Mechanical Engineering, Integral University Lucknow, India \\ ${ }^{3}$ University Polytechnic, Integral University Lucknow, India
}

\begin{abstract}
A three dimensional finite element model of friction stir welding was developed by using HyperWorks ${ }^{\circledR}$ codes in order to investigate the effect of process parameters on temperature distribution, strain rate and flow stress in the weld zone of aluminium alloy AA-6061 during the operation. The planning of simulation runs has been performed in accordance with the Taguchi L9 design with three factors-each three levels. The process parameters considered are tool rotation, welding speed and pin tilt angle. Regression analysis is performed in order to investigate the effect of process parameters on response parameters during friction stir welding. A mathematical relationship was also established between input and output parameters. This study indicates that rotational speed is the most significant parameter.
\end{abstract}

Keywords - Friction Sir Welding, Aluminium Alloy, Simulation, Temperature, Strain Rate, Flow Stress

\section{INTRODUCTION}

Friction stir welding is a thermo-mechanical based solid state joining process in which a rotational tool is moved about the joining edges of two metallic plates. FSW is fume less welding technology in which there is no need of filler material [11]. The joining is due to softening of metal at edges due to the heat developed by the rotational tool over the surface of metallic plates[12]. In this process, suitable temperature range plays a significant role and which is around $70-90 \%$ of the melting point [1]. There are several process parameters based on tool such as Rotational speed, Welding speed, Pin tilt angle, Pin diameter, Shoulder diameter, etc [14].

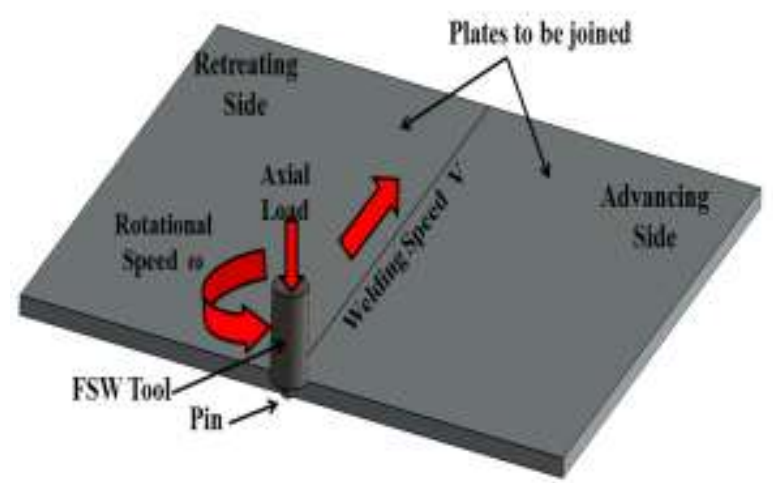

Fig.1 The schematic model of friction stir welding [5]

Abdul Arif, et al. [1] developed a finite element simulation with improved potential for the prediction of temperature during friction stir welding of aluminium alloy. They validated their developed model by comparing the results of with the experimental data. Armansyah et al. [2] performed transient thermal analysis through HyperWorks and they obtained temperature distribution for AA-6061 aluminium alloy and reported that there is decrease in amount of heat generation by increasing constant travelling speed at constant tool rotational speed. M.A. Siddiqui et al. [6] performed simulation for several rotational speeds at two constant sets of transverse speeds by using HyperWorks. They selected lower rotational and transverse speed based on the suitability of machine.. M.A. Siddiqui et al. [7] performed simulation of friction stir welding for the butt joint of Aluminium alloy AA6061 and results were validated with experimental data obtained from work of Zhili Feng et al. [15]. M.A. Siddiqui et al. [8] conducted virtual experiment of friction stir welding through HyperWorks for variable tool rotational speeds with constant travelling speed showed the variation in temperature distribution along the weld line of butt joint. M.A. Siddiqui et al. [9] performed simulation for friction stir welding of aluminium alloy AA-7075 and established relationship among the process parameters which were tool rotational speed and welding and response as maximum temperature. M. Nourani et al. [10] reported that the ANOVA method of the Taguchi L9 design and the full factorial analysis yielded similar parameter contributions. They also optimised the heat effected zone through simulation.

\section{PRESENT WORK}

In the present work, the effect of process parameters i.e. tool rotational speed $(\mathrm{R})$, welding speed $(\mathrm{S})$ and pin tilt angle $(\mathrm{A})$ on temperature $(\mathrm{T})$, strain rate $(\mathrm{Sr})$ and flow stress 
(Fs) during friction stir welding of aluminium alloy AA6061 is analyzed. The Simulation runs are designed according to Taguchi L9 and the simulation runs are conducted on Altair ${ }^{\circledR}$ HyperWorks ${ }^{\circledR}$. Regression analysis was performed in order to investigate the influence of process parameters. All other parameters were kept constant. A mathematical relation is also developed for the selected range of parameters.

Aluminum Alloy 6061-T6 is of the 6000 series Aluminum alloys which is mostly used in several application round the world. The physical \& thermal properties of Aluminium Alloy AA 6061 is shown in table I [2].

Table 1 Physical \& Thermal Properties of AA-6061

\begin{tabular}{|l|l|}
\hline Property & Values \\
\hline Density & $2.7 \mathrm{~g} / \mathrm{cm} 3$ \\
\hline Melting Point & $582-652^{\circ} \mathrm{C}$ \\
\hline Modulus of Elasticity & $68.9 \mathrm{GPa}$ \\
\hline Poisons Ratio & 0.33 \\
\hline Thermal Conductivity & $167 \mathrm{~W} / \mathrm{m}-\mathrm{k}$ \\
\hline Specific Heat Capacity & $0.869 \mathrm{~J} / \mathrm{g}{ }^{\circ} \mathrm{C}$ \\
\hline
\end{tabular}

The material for workpiece and tool are selected with reference to Armansyah et.al [2] for valid combinations. In the present work, two plates of aluminium alloy AA-6061 size $75 \mathrm{~mm} \times 200 \mathrm{~mm} \times 6 \mathrm{~mm}$ is selected. The properties of AA-6061 are shown in Table I. Friction stir welding tool is considered of hot die steel H-13. The shoulder diameter, shoulder length, pin diameter and pin length $15 \mathrm{~mm}, 50 \mathrm{~mm}$, $5 \mathrm{~mm} \& 5 \mathrm{~mm}$ respectively are shown in figure 2 .

\section{DESIGN OF SIMULATION RUNS}

Taguchi L9 orthogonal design [3] (shown in Table III) is used to analyze the effect of each processing parameter (the rotational speed, the transverse speed, and the pin tilt angle) on the temperature distribution along the weld line of the friction stir welded joints. This technique is adopted for reducing the number of runs and yields similar contribution as in full factorial design [10].

Table 2 Parameters and their level

\begin{tabular}{|l|l|l|l|l|}
\hline S.No & Parameter & $\begin{array}{l}\text { Level } \\
\text { I }\end{array}$ & $\begin{array}{l}\text { Level } \\
\text { II }\end{array}$ & $\begin{array}{l}\text { Level } \\
\text { III }\end{array}$ \\
\hline $\mathbf{1}$ & Tool Rotation (R) & 500 & 650 & 800 \\
\hline $\mathbf{2}$ & Welding Speed (S) & 4 & 5 & 5 \\
\hline $\mathbf{3}$ & Pin tilt angle (A) & 0 & 1 & 2 \\
\hline
\end{tabular}

Table 3 The Taguchi L9 design with three factors-each three levels

\begin{tabular}{|l|l|l|l|}
\hline Runs & $\begin{array}{l}\text { Tool } \\
\text { Rotation } \\
(\text { RPM })\end{array}$ & $\begin{array}{l}\text { Welding } \\
\text { Speed } \\
(\mathrm{mm} / \mathrm{s})\end{array}$ & $\begin{array}{l}\text { Pin Tilt } \\
\text { Angle } \\
(\text { Degree })\end{array}$ \\
\hline & R & S & A \\
\hline $\mathbf{1}$ & 500 & 4 & 0 \\
\hline $\mathbf{2}$ & 500 & 5 & 1 \\
\hline $\mathbf{3}$ & 500 & 6 & 2 \\
\hline $\mathbf{4}$ & 650 & 4 & 1 \\
\hline $\mathbf{5}$ & 650 & 5 & 2 \\
\hline $\mathbf{6}$ & 650 & 6 & 0 \\
\hline $\mathbf{7}$ & 800 & 4 & 2 \\
\hline $\mathbf{8}$ & 800 & 5 & 0 \\
\hline $\mathbf{9}$ & 800 & 6 & 1 \\
\hline
\end{tabular}

\section{SIMULATION PROCEDURE}

In the present work, Manufacturing Solutions module of Altair $^{\circledR}$ HyperWorks ${ }^{\circledR}$ version 12.0 is used for finite element simulation of friction stir welding. HyperWorks ${ }^{\circledR}$ is used for simulation and finite element analysis of friction stir welding process considering the tool as a steady state heat source [4].

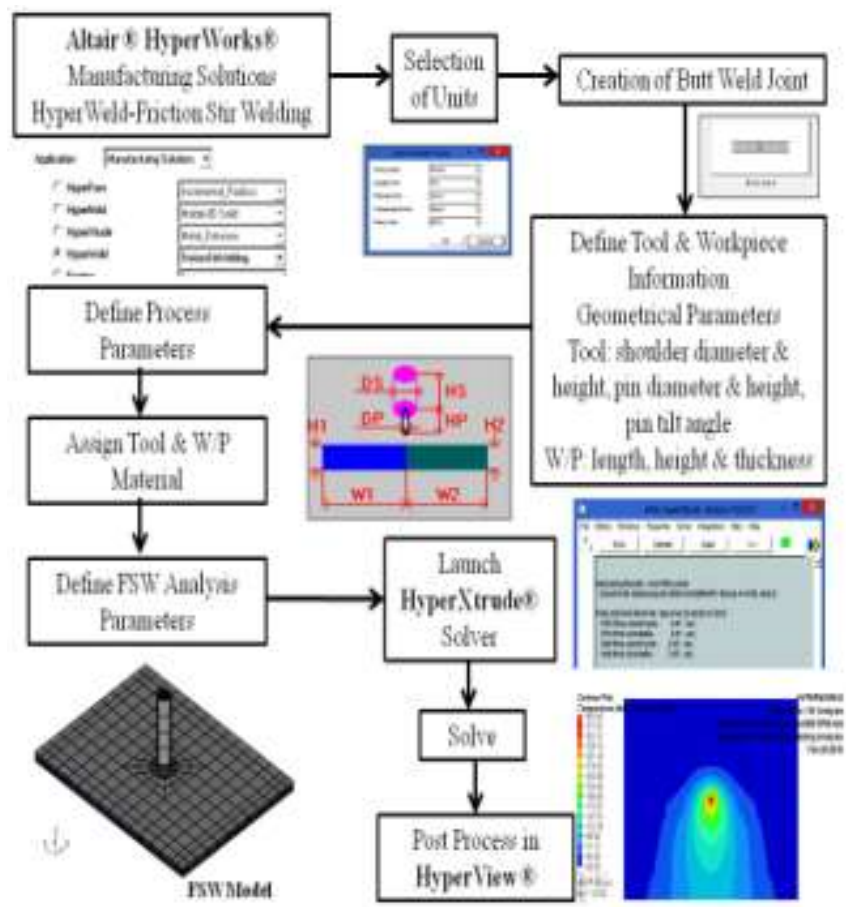

Fig. 2. Flowchart of Friction Stir Welding Simulation

The model has 3200 quadrilateral elements and 3907 active nodes. Hex20 elements were used for thermo mechanical modeling, these elements are three dimensional, $2^{\text {nd }}$ order hexahedral elements with 20 nodes. 
Table 4. The Taguchi L9 design with three factors-each three levels, along with the obtained response values from the corresponding runs.

\begin{tabular}{|l|l|l|l|l|l|l|}
\hline Designation & $\begin{array}{l}\mathbf{R} \\
(\mathbf{r p m})\end{array}$ & $\begin{array}{l}\mathbf{S} \\
(\mathbf{m m} / \mathbf{s})\end{array}$ & $\begin{array}{l}\text { A } \\
(\mathbf{d e g r e e})\end{array}$ & $\begin{array}{l}\mathbf{T} \\
\left({ }^{\mathbf{o}} \mathbf{C}\right)\end{array}$ & $\begin{array}{l}\text { Fs } \\
(\mathbf{M P a})\end{array}$ & $\begin{array}{l}\mathbf{S r} \\
\left(\mathbf{s}^{-1}\right)\end{array}$ \\
\hline S1 & 500 & 4 & 0 & 374.98 & 60 & 45.57 \\
\hline S2 & 500 & 5 & 1 & 369.75 & 64.08 & 48.09 \\
\hline S3 & 500 & 6 & 2 & 391.13 & 63.12 & 52.73 \\
\hline S4 & 650 & 4 & 1 & 441.47 & 47.91 & 59.25 \\
\hline S5 & 650 & 5 & 2 & 445.68 & 51.5 & 66.43 \\
\hline S6 & 650 & 6 & 0 & 406.41 & 55.11 & 61.79 \\
\hline S7 & 800 & 4 & 2 & 497.45 & 42.05 & 80.33 \\
\hline S8 & 800 & 5 & 0 & 454.17 & 44.47 & 71.45 \\
\hline S9 & 800 & 6 & 1 & 458.87 & 45.28 & 72.96 \\
\hline
\end{tabular}

\section{RESULTS AND DISCUSSSION}

\subsection{Finite Element Analysis}

In the present work, HyperWorks ${ }^{\circledR}$ is used for simulation of friction stir welding process in order to generate butt joint of Aluminium alloy AA6061 plates. This section presents the temperature, strain rate and flow stress pattern developed during friction stir welding.

\subsubsection{Temperature}

Figure 3 to 5 shows the simulation results of temperature profile obtained through finite element analysis by considering the tool as steady state heat source. It is observed that the temperature distribution is uniform about the centre line or weld line along which the tool is moving.

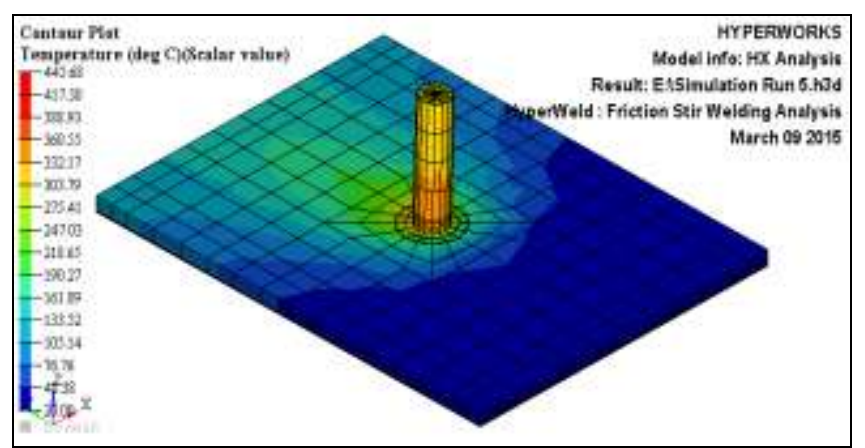

Fig.3 Isometric view of simulated model of butt joint of AA6061 during friction stir welding process showing temperature contours.

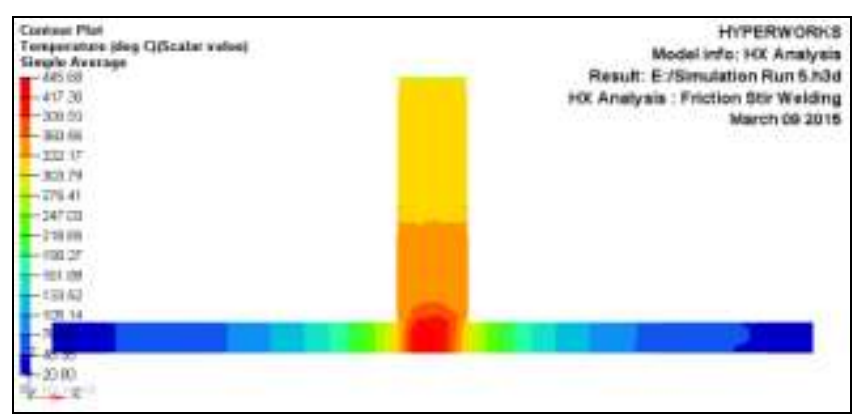

Fig.4 Cross sectional view of simulated model of friction stir welding process showing temperature contours.

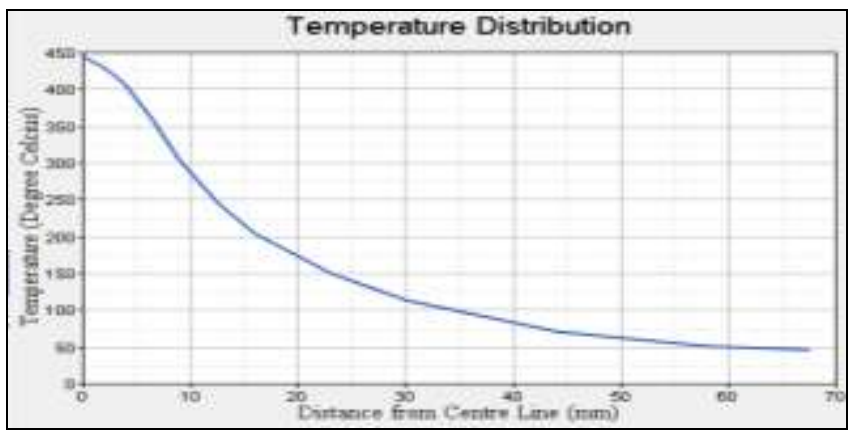

Fig.5 Temperature distribution for advancing side during finite element analysis of friction stir welding with the position of tool in mid of the plates.

\subsubsection{Strain Rate}

Figure 6 and 7 shows the simulation results of strain rate profile obtained through finite element analysis by considering the tool as steady state heat source. It is observed that the maximum strain is in advancing side of tool and maximum value of strain rate is located near the pin tip circumference which is in contact with the workpiece.

Figure 8 shows the strain rate as a function of distance from the weld line or centre line along which the tool is moving in y direction. It is observed that the strain rate decreases as we move away from centre line as it is directly proportional to the rate of deformation which is maximum at pin workpiece interface.

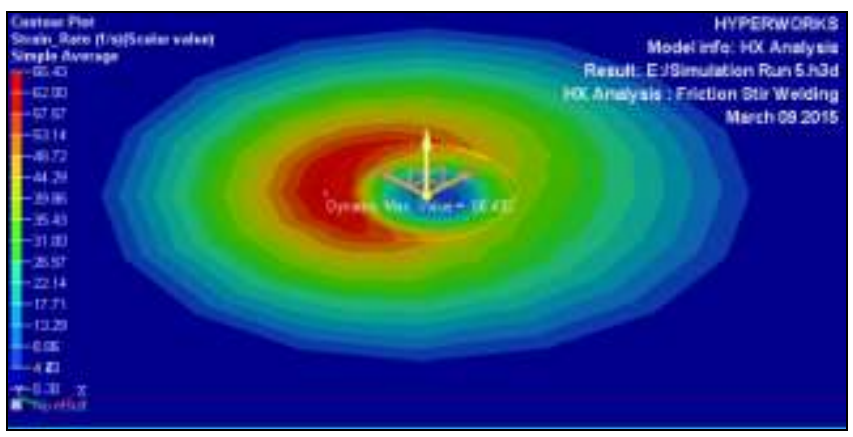

Fig.6 Isometric view of simulated model of friction stir welding process showing strain rate contours near pin workpiece interface with maximum value at periphery of pin. 


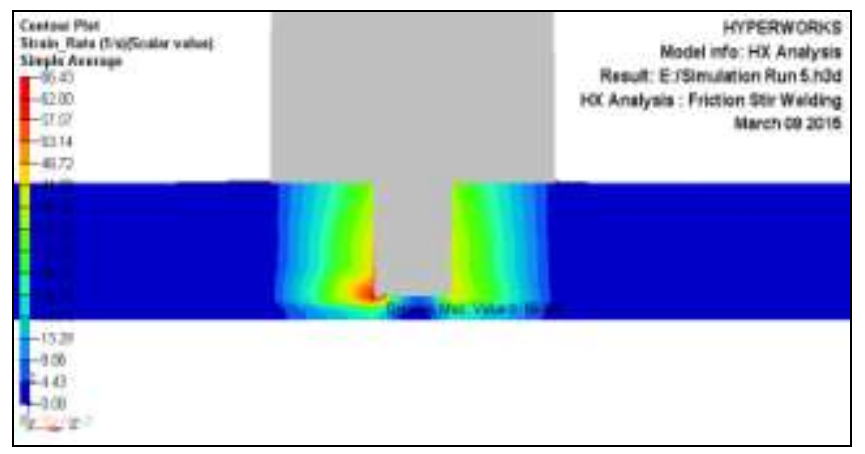

Fig.7 Cross sectional view of strain rate contours observed at pin interface.

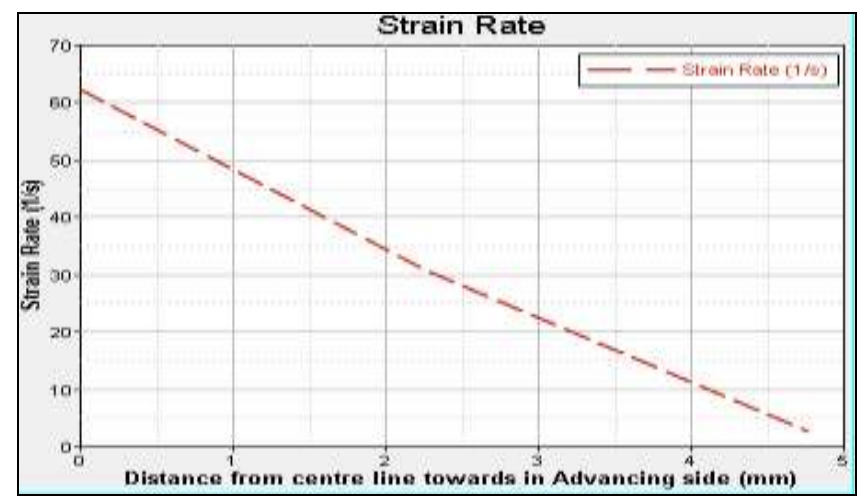

Fig.8 Flow stress distribution as a function of distance from centre line during friction stir welding with tool in mid of the plates.

\subsubsection{Flow Stress}

Figure 9 and 10 shows the simulation results of flow stress profile obtained through finite element analysis by considering the tool as steady state heat source. It is observed that flow stress is reduced at the centre line through which the tool is transverse.

Figure 11 shows the flow stress as a function of distance from the weld line or centre line along which the tool is moving in y direction. It is observed that the flow stress is minimum below the pin tip as this region has high rate of plastic deformation due to softening of alloy. The graph also shows bulge at advancing side which means flow stress in advancing side is relatively less that retreating side near the centre line.

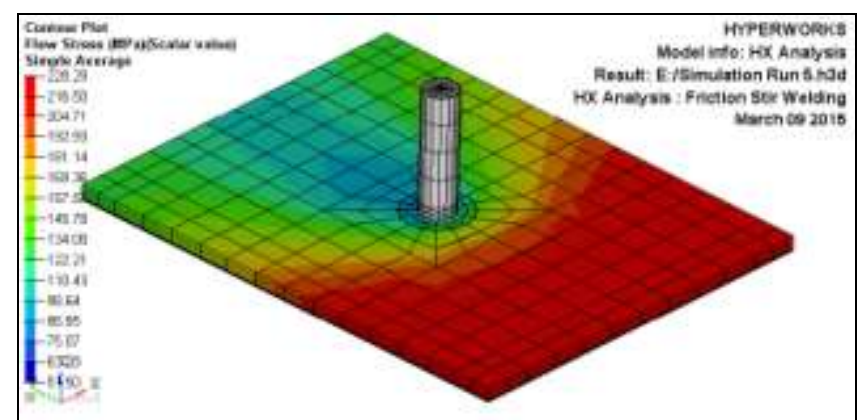

Fig.9 Isometric view of simulated model of friction stir welding process showing flow stress contours.

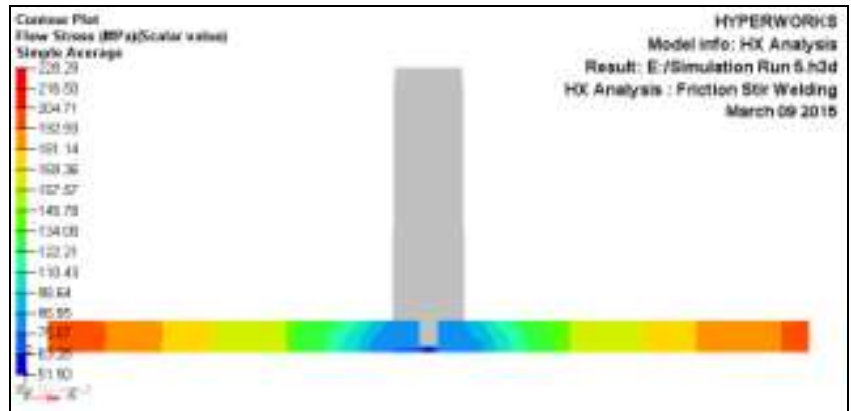

Fig.10 Cross sectional view of simulated model of friction stir welding process showing flow stress contours.

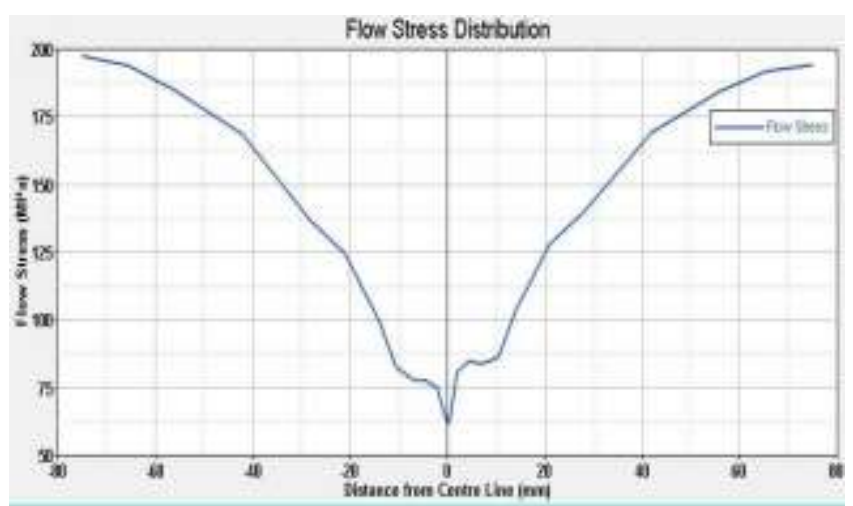

Fig.11 Flow stress distribution as a function of distance from centre line during friction stir welding with tool in mid of the plates.

\subsection{Regression Analysis}

In friction stir welding process, the sound weld joint depends upon the major responses such as temperature, strain rate and flow stress achieved in tool-work piece interphase. As far as effect of process parameters on responses are concerned, the observations are done on the basis of plots for the data obtained from simulation. The main effect \& interaction plots are obtained by statistical tool Minitab [13].

\subsubsection{Temperature}

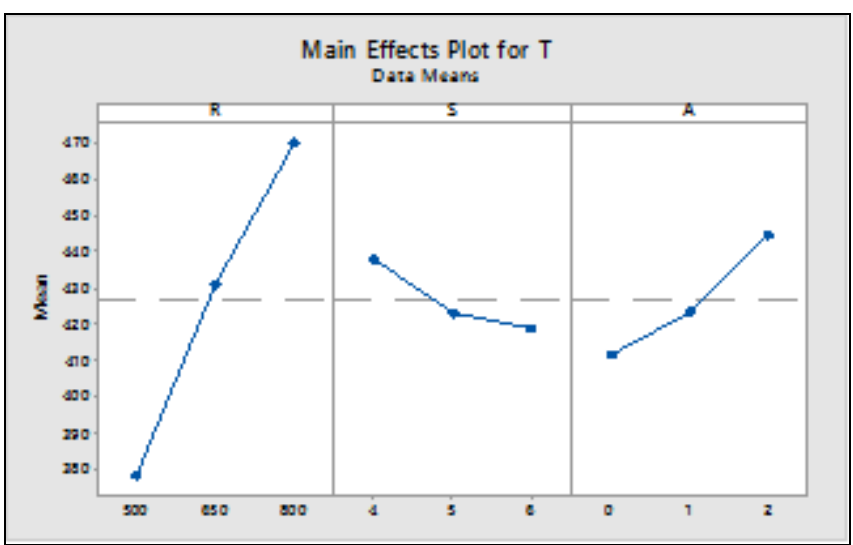

Fig.12 Graphical representation of main effect of Tool rotational speed (R), Welding speed (WS) and Pin tilt Angle (A) on Maximum Temperature during friction stir welding of Aluminium Alloy AA-6061. 


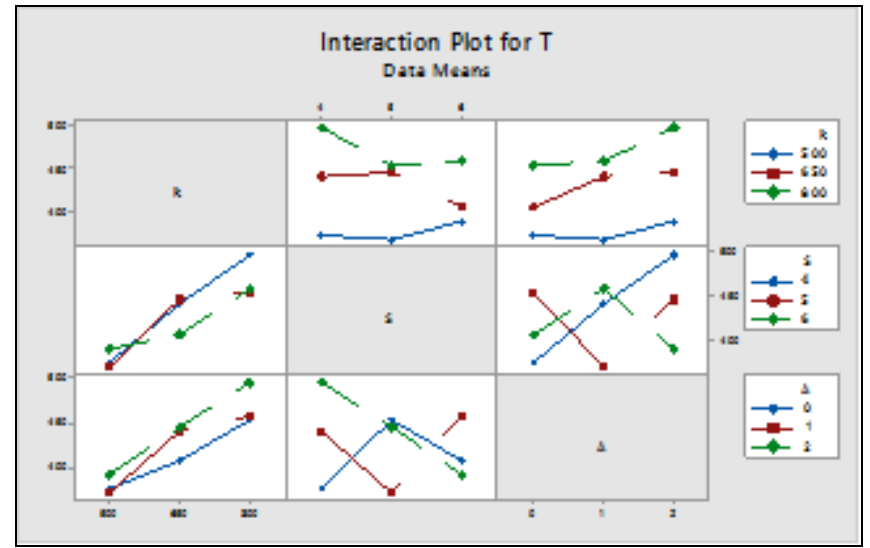

Fig.13 Graphical representation of Interaction effect of tool rotational speed $(\mathrm{R})$, welding speed $(\mathrm{S})$ and pin tilt angle (A) on Maximum Temperature during friction stir welding of Aluminium Alloy AA-6061.

The relationship among tool rotational speed (R), welding speed (S) and pin tilt angle (A) and maximum temperature (T) during friction stir welding of aluminium alloys 6061 is obtained by regression analysis within the range of tool rotational speed (R) of 500-800 rpm, welding speed (S) of 4$6 \mathrm{~mm} / \mathrm{s}$ and pin tilt angle (A) of $0-2^{\circ}$. The equation or regression model obtained is as follows:

$$
\mathrm{T}=259.8+0.3051 \mathrm{R}-9.58 \mathrm{~S}+16.45 \mathrm{~A}
$$

\subsubsection{Strain Rate}

Graph (figure 14) shows the main effect of process parameters i.e. rotational speed (R), welding speed $(\mathrm{S})$ and pin tilt angle (A) on Strain rate $(\mathrm{Sr})$.

Graph (figure 15) shows the interaction effect of process parameters i.e. rotational speed (R), welding speed (S) and pin tilt angle (A) on Strain rate.

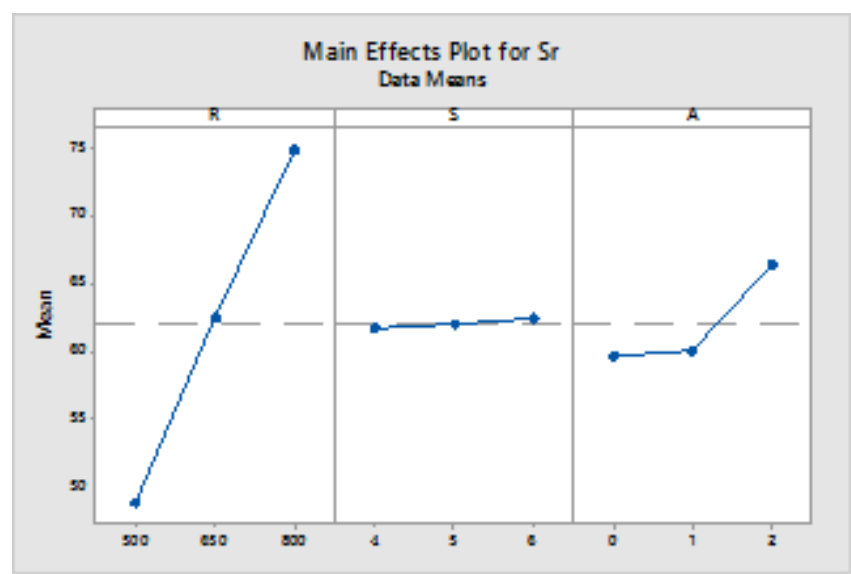

Fig.14 Graphical representation of main effect of Tool rotational speed (R), Welding speed (WS) and Pin tilt Angle (A) on Maximum Temperature during friction stir welding of Aluminium Alloy AA-6061.

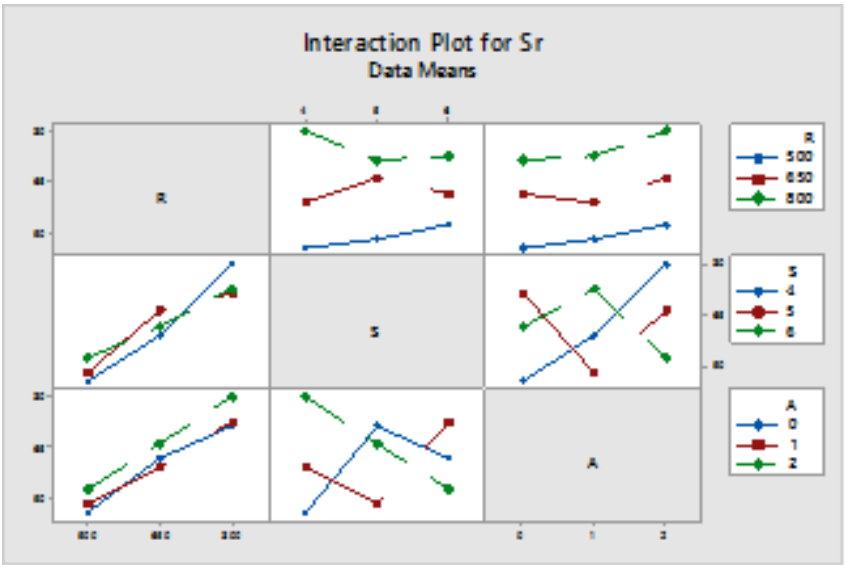

Fig.15 Graphical representation of Interaction effect of tool rotational speed $(\mathrm{R})$, welding speed $(\mathrm{S})$ and pin tilt angle $(\mathrm{A})$ on Maximum Temperature during friction stir welding of Aluminium Alloy AA-6061.

The relationship among tool rotational speed (R), welding speed (S) and pin tilt angle (A) and strain rate $(\mathrm{Sr})$ during friction stir welding of aluminium alloys 6061 is obtained by regression analysis within the range of tool rotational speed (R) of 500-800 rpm, welding speed (S) of 4-6 mm/s and pin tilt angle (A) of $0-2^{\circ}$. The equation or regression model obtained is as follows:

\section{$\mathrm{Sr}=0.09+0.08706 \mathrm{R}+0.388 \mathrm{~S}+3.447 \mathrm{~A}$}

\subsubsection{Flow-Stress}

Graph (figure 16) shows the main effect of process parameters i.e. rotational speed (R), welding speed (S) and pin tilt angle (A) flow stress.

Graph (figure 17) shows the interaction effect of process parameters i.e. rotational speed (R), welding speed $(\mathrm{S})$ and pin tilt angle (A) on flow stress.

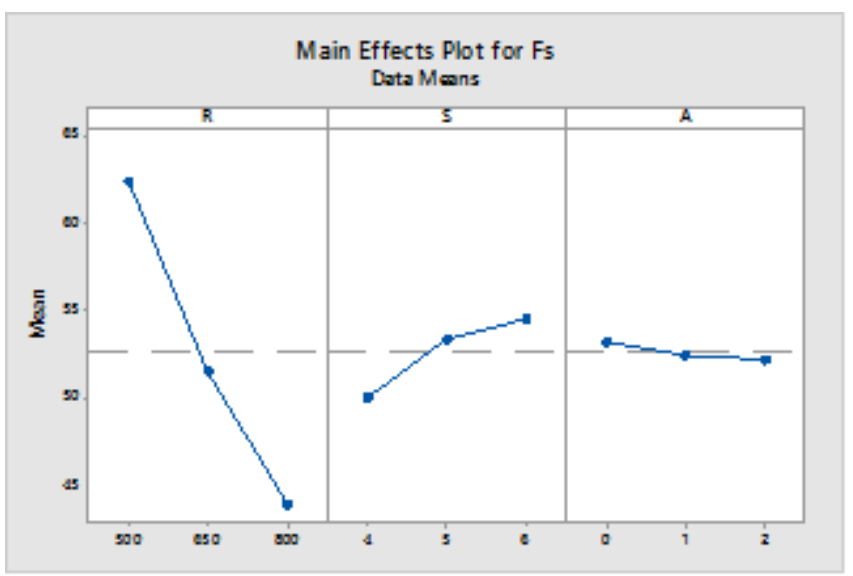

Fig.16 Graphical representation of main effect of Tool rotational speed (R), Welding speed (WS) and Pin tilt Angle (A) on Maximum Temperature during friction stir welding of Aluminium Alloy AA-6061. 


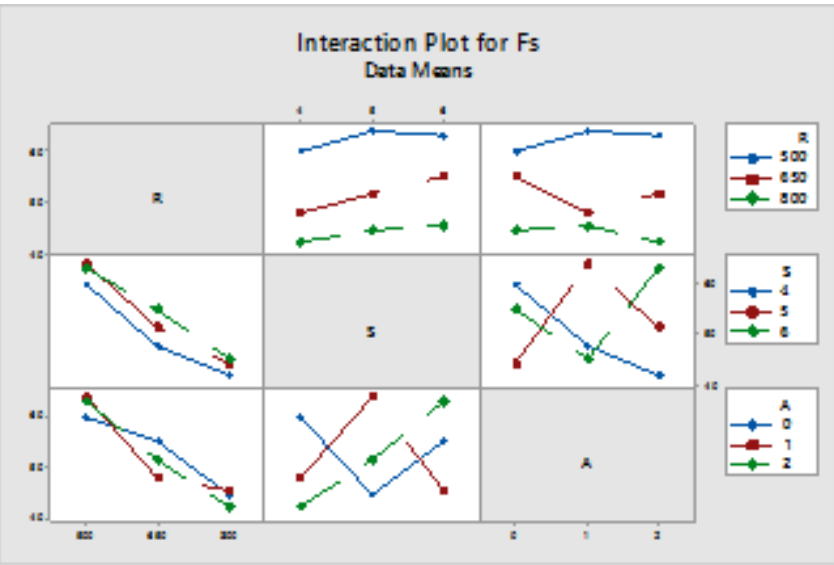

Fig.17 Graphical representation of Interaction effect of tool rotational speed $(\mathrm{R})$, welding speed $(\mathrm{S})$ and pin tilt angle (A) on Maximum Temperature during friction stir welding of Aluminium Alloy AA-6061.

The relationship among tool rotational speed (R), welding speed (S) and pin tilt angle (A) and flow stress (Fs) during friction stir welding of aluminium alloys 6061 is obtained by regression analysis within the range of tool rotational speed (R) of 500-800 rpm, welding speed (S) of 4-6 mm/s and pin tilt angle (A) of $0-2^{\circ}$. The equation or regression model obtained is as follows:

$$
\text { Fs }=81.82-0.06156 R+2.258 \mathrm{~S}-0.485 \mathrm{~A}
$$

Table 5. Result summary: Effect of parameters.

\begin{tabular}{|l|l|l|l|}
\hline $\begin{array}{l}\text { Parameters } \\
\text { (increase) }\end{array}$ & $\begin{array}{l}\text { Temperature } \\
\left({ }^{\circ} \mathrm{C}\right)\end{array}$ & $\begin{array}{l}\text { Strain } \\
\text { Rate } \\
(1 / \mathrm{s})\end{array}$ & $\begin{array}{l}\text { Flow } \\
\text { stress } \\
(\mathrm{MPa})\end{array}$ \\
\hline $\begin{array}{l}\text { Tool Rotation } \\
(\mathrm{rpm})\end{array}$ & Increase & Increase & Decrease \\
\hline $\begin{array}{l}\text { Welding Speed } \\
(\mathrm{mm} / \mathrm{s})\end{array}$ & Decrease & Decrease & Increase \\
\hline $\begin{array}{l}\text { Pin tilt angle } \\
(\text { degree })\end{array}$ & Increase & Increase & Decrease \\
\hline
\end{tabular}

Table V shows the summary of results obtained from regression analysis of the data obtained for temperature, strain rate and flow stress through simulation of friction stir welding of aluminium alloy. The table shows the effects of parameters.

\section{CONCLUSION}

In case of friction stir welding process, suitable temperature range, strain rate and flow stress if responsible for successful joining of two alloy plates. In order to analyze the effect of process parameters such as tool rotational speed, pin tilt angle and welding speed on the temperature distribution, the simulation of friction stir welding was performed in accordance with Taguchi L9 orthogonal design. The Regression analysis was performed in order to establish mathematical relation among the parameters can be used for prediction of temperature, strain rate and flow stress during friction stir welding of AA-6061 for the selected range of process parameters. From the ANOVA, it is observed that tool rotational speed has $83.98 \%, 91.19 \%$ and $91.72 \%$ contribution on peak temperature, strain rate and flow stress respectively. It is concluded that the most significant parameter is tool rotational speed which has high percentage of contribution on responses.

\section{ACKNOWLEDGEMENT}

Authors are highly thankful to the Technical Head, CADCAM $^{\circledR}$ Centre Training Services Pvt. Ltd, Kanpur, India for providing assistance and access to the lab and software facilities to conduct simulations on Friction Stir Welding.

\section{REFERENCES}

[1] Abdul Arif, Saurabh Kumar Gupta, K.N.Pandey, "Finite Element Modelling for Validation of Maximum Temperature in Friction Stir Welding of Aluminium Alloy", 3rd International Conference on Production and Industrial Engineering, CPIE- 2013.

[2] Armansyah, I. P. Almanar, M. Saiful Bahari Shaari, M. Shamil Jaffarullah, Nur'amirah Busu, M. Arif Fadzleen Zainal Abidin, M. Amlie A. Kasim., Temperature Distribution in Friction Stir Welding Using Finite Element Method, International Journal of Mechanical, Aerospace, Industrial and Mechatronics Engineering Vol:8 No:10, 2014.

[3] K. Ranjit Roy, "A Primer on the Taguchi Method," 2nd Edition, Society of Manufacturing Engineers, Michigan,2010.

[4] Manufacturing Solution Tutorials, HyperWorks 12.0., Altair Engineering Inc.

[5] Mohd Anees Siddiqui, S. A. H. Jafri, Shahnawaz Alam, "Validation of Maximum Temperature during Friction Stir Welding of Butt Joint of Aluminium Alloy by using HyperWorks." International Journal of Engineering Research and Technology. Vol. 4. No. 04, April 2015

[6] Mohd Anees Siddiqui, S. A. H. Jafri, Shahnawaz Alam, "Pre-Experimental Simulation For Prediction Of Rotational Speeds For Required Range Of Temperature In Friction Stir Welding Of Butt Joint Of Aluminium Alloy", International Journal of Advance Research in Science and Engineering, Vol 4, Special Issue, A R Research publication, Feb 2015.

[7] Mohd Anees Siddiqui, S. A. H. Jafri, Shahnawaz Alam, "Validation of Maximum Temperature during Friction Stir Welding of Butt Joint of Aluminium Alloy by using HyperWorks", International Journal of Engineering Research \& Technology, Vol 4,Issue 4, ESRSA publication, April 2015.

[8] Mohd Anees Siddiqui, S. A. H. Jafri, Shahnawaz Alam, Study of Simulated Temperature of Butt Joint during Friction Stir Welding Of Aluminium Alloy by Using Hyperworks, Vol.5 Issue.1, Int. Journal of Engineering Research and Applications, Jan 2015.

[9] Mohd Anees Siddiqui S.A.H. Jafri K.M.Moeed S. Alam, Investigation of Effect of Process Parameters on Maximum Temperature During Friction Stir Welding of Aluminium Alloy, Vol.3 Issue.10, 
International Journal for Scientific Research \& Development, Dec 2015.

[10] Mohamadreza Nourani, Abbas S. Milani, Spiro Yannacopoulos, Taguchi Optimization of Process Parameters in Friction Stir Welding of 6061 Aluminum Alloy: A Review and Case Study, SciRes, Eng, Feb 2011.

[11] P. L. Threadgill, A. J. Leonard, H. R. Shercliff, and P. J. Withers, "Friction stir welding of aluminum alloys," Int Mater Rev, vol. 54, pp. 49-93, 2009.

[12] R.S. Mishra, Z.Y. Ma, Friction stir welding and processing, Materials Science and Engineering, Elsevier, August 2005.

[13] Shonda \& Jeffrey Sklar, Minitab Manual, Pearson Education, Inc., 2013

[14] Terry Khaled, "An Outsider Looks at Friction Stir Welding”, Report: ANM-112N-05-06, Federal Aviation Administration, Paramount Boulevard, Lakewood July 2005

[15] Zhili Feng, Xun-Li Wang, Stan A. David, and Phil Sklad, Modeling of residual stresses and property distributions in friction stir welding of aluminium alloy 6061-T6, 5thInternational Friction Stir Welding Symposium, Metz, France, 2004. 